\title{
Editorial
}

\section{Health Risks of Nuclear-Power-Plant Accidents}

While I am writing this article in June 2011, I don't foresee any such risks for our people in near future. But I believe many of us will not agree with this statement because of the recent Fukushima Daiichi Nuclear Power Plant disaster in 11 March 2011 which created much apprehension amongst us. Fukushima Daiichi Nuclear Power Plant disaster was a mere accident which was a consequence of a 9.0 magnitude earthquake and the subsequent tsunami. The total number of people who died in the earth quack and the tsunami that it generated is still being assessed, but the official estimation already exceeds $14,000 .{ }^{1}$ Though we are not a nuclear power, being surrounded by the countries having powerful nuclear reactors does put us in some risk no mater how remote it may be. The reason is clear, the havoc produced by nuclear power plant accident will not remain limited to the country of origin but spread like anything and can run after miles and miles through air, water, food etc. and the effects may remain for hundreds of years. The situation at Fukushima, though still in daily flux, will probably end up ranking between these two historical accidents in terms of radiation releases and health consequences. The other potential hazard from radiation is the terrorist attack by nuclear weapons. But the hazards from the two are far far different and are not comparable.

The amount of radiation (i.e., radiation dose) absorbed by the patient's tissue is highly predictive of its biological effects. Such doses are defined as the amount of energy of ionizing radiation deposited per unit of tissue mass at a specific point. $^{2}$

Human radiation exposure as a result of reactor accidents is characterized in three ways, total or partial body exposure as a result of close proximity to a radiation source, external contamination, and internal contamination. All three types can affect a person in a radiation accident. Total or partial body exposure occurs when an external source irradiates the body either superficially or deeply into internal organs, with the depth depending on the type and energy of the radiation involved. For example, beta radiation travels only a short distance in tissue, depending on its energy, and can be a significant source of skin damage. High-energy gamma radiation, however, can penetrate deeply. In previous reactor accidents, only plant workers and emergency personnel who were involved in the aftermath had substantial total or partial body exposure. Persons who have had total or partial body exposure but no contamination are not radioactive and therefore cannot expose their caregivers to radiation. External contamination occurs when the fission products settle on human beings, thereby exposing skin or internal organs. Populations living near a reactor accident may be advised to remain indoors for a period to minimize the risk of external contamination. Internal contamination occurs when fission products are ingested or inhaled or enters the body through open wounds. This is the primary mechanism through which large populations around a reactor accident can be exposed to radiation ${ }^{2}$. After Chernobyl, approximately 5 million people in the region may have had excess radiation exposure, primarily through internal contamination. ${ }^{3}$

Reactor accidents can release a variety of radioisotopes into the environment. The health threat from each radioisotope depends on an assortment of factors. Radioisotopes with a very short half-life (e.g., 67 hours for molybdenum-99) or a very long half-life (e.g., 24,400 years for plutonium-239), those that are gaseous (e.g., xenon-133), and those that are not released in substantial quantities (e.g., plutonium-238) do not cause substantial internal or external contamination in reactor accidents. In contrast, iodine-131 can be an important source of morbidity because of its prevalence in reactor discharges and its tendency to settle on the ground. When iodine-131 is released, it can be inhaled or consumed after it enters the food chain, primarily through contaminated fruits, vegetables, milk, and groundwater.Once it enters the body, iodine-131 rapidly accumulates in the thyroid gland, where it can be a source of substantial doses of beta radiation. ${ }^{4,5}$

Ionizing radiation may interact directly with intracellular targets or may interact with other molecules (eg, water) to produce free radicals that, in turn, reach and damage its target (eg, DNA, mRNA, proteins, plasma membrane). Radiosensitivity varies directly with the rate of cellular proliferation. Rapidly dividing cells are more profoundly affected. The process depends on number of future divisions. Long-lived gonadal and hematopoietic stem cells fall into this category. Radio sensitivity varies indirectly with the degree of morphologic and functional differentiation. As an example, cells at the growth plate in bone, which have not yet developed into bone or cartilage, are more sensitive than those of the diaphysis. Accordingly, growth arrest of bone is commonly seen after radiation exposure to the growth plate in children, as may occur in the treatment of malignancy. Variation in sensitivity to radiation is an inherited genetic 
trait, although candidate gene studies have been largely unsuccessful in identifying the genetic variants underlying most phenotypes. ${ }^{6}$

While all tissues composed of short-lived cells are either directly or indirectly affected by radiation, the most critically affected tissues in adults are spermatocytes in the testis, hematopoietic precursor cells in the bone marrow and crypt cells in the intestines. ${ }^{4,7}$

Following exposure of either all or most of the human body to ionizing radiation, Acute Radiation Sickness (ARS) can develop. The clinical manifestations of ARS reflect the dose and type of radiation as well as the part of the body exposed. ${ }^{8}$ ARS manifests as three major groups of signs and symptoms: hematopoietic, gastrointestinal, and neurovascular. There are four major stages in ARS: prodrome, latent phase, illness, and either recovery or death. The higher the radiation doses, the shorter and more severe each stage. The prodrome appears within minutes to 4 days post exposure; lasts between a few hours to a few days; and can include nausea, vomiting, anorexia, and diarrhea. At the end of the prodrome, ARS progresses to the latent phase. Minimal or no symptoms are present during the latent phase, which commonly lasts up to 2.5 weeks, but can last up to 6 weeks. The duration depends on the radiation dose, the health of the patient, and the coexisting illness or injury. Following the latent phase, the exposed person manifests illness that may eventuate in recovery or lead to death. ${ }^{8}$

With exposure to doses $<1 \mathrm{~Gy}$, ARS is generally mild. At this dose symptoms can be minimal or nonexistent, even if the entire body is exposed to penetrating radiation. The clinical picture will mainly be transient depression of bone marrow (lymphopenia) that lasts up to 2 to 3 weeks and then recovers. ARS is significantly more acute and severe with exposure to very high doses $\longrightarrow 30 \mathrm{~Gy}$. At this dose the prodrome appears in minutes and is followed by 5 to $6 \mathrm{~h}$ of latency before a cardiovascular collapse occurs secondary to irreversible damage to the microcirculation. ${ }^{8}$

Acute radiation sickness has not been seen in the general population in association with a nuclear-reactor accident. The treatment of ARS is focused on maintaining homeostasis, giving damaged organs the chance to recover. Aggressive support is given to every damaged system. Treatment for the hematopoietic system includes mainly therapy for neutropenia and infection, transfusion and blood products as needed, and hematopoietic growth factors. The value of bone marrow transplantation in this situation is questionable. None of the transplants that were performed among the victims of the nuclear reactor accident in
Chernobyl proved successful. Another major component of the treatment of ARS is partial or total parenteral nutrition, to bypass the damaged GI system. For blast and thermal injuries, standard therapy for trauma is given. Psychological support is essential in many cases. 7,8

Although exposure to nuclear-reactor fallout does not cause acute illness, it may elevate long-term cancer risks. Studies of the Japanese atomic-bomb survivors showed clearly elevated rates of leukemia and solid cancers, even at relatively low total body doses. ${ }^{9,10}$ However, there is strong evidence of an increased rate of secondary thyroid cancers among children who have ingested iodine-131. Careful studies of children living near the Chernobyl plant (which included estimates of the thyroid radiation dose) suggest that the risk of thyroid cancer increased by a factor of 2 to 5 per 1 Gy of thyroid dose. ${ }^{11-13}$ In accidents in which iodine-131 is released, persons in affected areas should attempt to minimize their consumption of locally grown produce and groundwater. However, since the half-life of iodine-131 is only 8 days, these local resources should not contain substantial amounts of iodine-131 after 2 to 3 months. From public health standpoint, residents may take potassium iodide to block the uptake of iodine-131 in the thyroid. To be most effective, prophylactic administration of potassium iodide should occur before or within a few hours after iodine-131 exposure. The administration of the drug more than a day after exposure probably has limited effect, unless additional or continuing exposure is expected. ${ }^{14}$ Although potassium iodide can have toxic effects, the Polish experience with en masse administration of the drug after Chernobyl was reassuring as per studies from post Chernobyl disaster ${ }^{15}$

Nuclear-reactor accidents are very rare, few medical practitioners have direct experience in treating patients who have been exposed to radiation or in the overall public health response. Organizations that could be involved in either activity because of their proximity to a power plant or their role in the health system must put detailed algorithmic response plans in place and practice them regularly. A critical component of the response, with respect to both treatment of individual patients and interaction with the community, is clear communication about exposure levels and corresponding risk, with an eye toward widespread public apprehension about acute radiation sickness and long-term cancer risks.

$25^{\text {th }}$ June, 2011

Professor MA Jalil Chowdhury 


\section{References:}

1. Christodouleas JP, Forrest RD, Ainsley CG, Tochner, Z , Hahn SM, \& Glatstein E. Short-Term and Long-Term Health Risks of Nuclear-Power-Plant Accidents. New Engl J Med 2011; 364: 2334-2341

2. National Research Council, Committee on the Biological effects of Ionizing Radiation. Health Effects of Exposure to Low Levels of Ionizing Radiation, BEIR V. Washington, DC: National Academy Press 1990.

3. Vienna: International Atomic Energy Agency, 2006. (IAEA publication no. IAEA/ PI/A.87 Rev.2 / 06-0918.) (http:// www .iaea.org/Publications/Booklets/Chernobyl/ chernobyl.pdf.)

4. Chernobyl: assessment of radiological and health impacts. 2002 Update of Chernobyl: ten years on. Paris: Nuclear Energy Agency of the Organization for Economic Cooperation and Development, 2003. (http://www.oecdnea.org/rp/chernobyl/.)

5. Kesminiene A, Evrard AS, Ivanov VK, et al. Risk of hematological malignancies among Chernobyl liquidators. Radiat Res 2008; 170:721-35.

6. Health effects of the Chernobyl accident and special health care programmes. Geneva: World Health Organization, 2006. (http://www.who.int/ionizing_radiation/ chernobyl/ who_chernobyl_report_2006.pdf.)

7. Tochner ZA, Glatstein E. Radiation bioterrorism. In: Fauci AS, Braunwald E, Kasper DL, et al., eds. Harrison's principles of internal medicine. 17th ed. New York: McGrawHill Medical, 2008:1358- 64.

8. Preston DL, Kusumi S, Tomonaga M, et al. Cancer incidence in atomic bomb survivors. Part III. Leukemia, lymphoma and multiple myeloma, 1950-1987. Radiat Res 1994; 137:S68-97. [Erratum, Radiat Res 1994; 139:129.]

9. Preston DL, Ron E, Tokuoka S, et al. Solid cancer incidence in atomic bomb survivors: 1958-1998. Radiat Res 2007;168: $1-64$.

10. Tronko MD, Howe GR, Bogdanova TI, et al. A cohort study of thyroid cancer and other thyroid diseases after the Chernobyl accident: thyroid cancer in Ukraine detected during first screening. J Natl Cancer Inst 2006; 98:897-903.

11. Zablotska LB, Ron E, Rozhko AV, et al. Thyroid cancer risk in Belarus among children and adolescents exposed to radioiodine after the Chernobyl accident. $\mathrm{Br} \mathrm{J}$ Cancer 2011; 104:181-7.

12. Brenner AV, Tronko MD, Hatch M, et al. I-131 Doseresponse for incident thyroid cancers in Ukraine related to the Chernobyl accident. Environ Health Perspect 2011 March 14 (Epub ahead of print).

13. Shakhtarin VV, Tsyb AF, Stepanenko VF, Orlov MY, Kopecky KJ, Davis S. Iodine deficiency, radiation dose, and the risk of thyroid cancer among children and adolescents in the Bryansk region of Russia following the Chernobyl power station accident. Int J Epidemiol 2003; 32:584-91.

14. Nauman J, Wolff J. Iodide prophylaxis in Poland after the Chernobyl reactor accident: benefits and risks. Am J Med 1993; 94:524-32. 